\title{
Initial load-to-failure and failure analysis in single- and double-row repair techniques for rotator cuff repair
}

\author{
M. H. Baums • G. H. Buchhorn · F. Gilbert • \\ G. Spahn $\cdot$ W. Schultz $\cdot$ H.-M. Klinger
}

Received: 1 July 2009 / Published online: 5 January 2010

(C) The Author(s) 2009. This article is published with open access at Springerlink.com

\begin{abstract}
Aim This experimental study aimed to compare the loadto-failure rate and stiffness of single- versus double-row suture techniques for repairing rotator cuff lesions using two different suture materials. Additionally, the mode of failure of each repair was evaluated.

Method In 32 sheep shoulders, a standardized tear of the infraspinatus tendon was created. Then, $n=8$ specimen were randomized to four repair methods: (1) Double-row Anchor Ethibond ${ }^{\circledR}$ coupled with polyester sutures, USP No. 2; (2) Double-Row Anchor $\mathrm{HiFi}^{\circledR}$ with polyblend polyethylene sutures, USP No. 2; (3) Single-Row Anchor Ethibond ${ }^{\circledR}$ coupled with braided polyester sutures, USP No. 2; and (4) Single-Row Anchor $\mathrm{HiFi}^{\circledR}$ with braided polyblend polyethylene sutures, USP No. 2. Arthroscopic MasonAllen stitches were placed (single-row) and combined with medial horizontal mattress stitches (double-row). All specimens were loaded to failure at a constant displacement rate on a material testing machine.

Results Group 4 showed lowest load-to-failure result with $155.7 \pm 31.1 \mathrm{~N}$ compared to group $1(293.4 \pm 16.1 \mathrm{~N})$ and group $2(397.7 \pm 7.4 \mathrm{~N})(P<0.001)$. Stiffness was highest in group $2(162 \pm 7.3 \mathrm{~N} / \mathrm{mm})$ and lowest in group 4
\end{abstract}

M. H. Baums ( $₫) \cdot$ G. H. Buchhorn · F. Gilbert · W. Schultz ·

H.-M. Klinger

Department of Orthopaedic Surgery,

University of Göttingen Medical Centre (UMG),

Georg-August-University, Robert-Koch-Street 40,

37075 Göttingen, Germany

e-mail:mbaums@t-online.de

G. Spahn

Clinic of Orthopaedic Surgery and Traumatology Eisenach,

Eisenach, Germany
$(84.4 \pm 19.9 \mathrm{~mm})(P<0.001)$. In group 4 , the main cause of failure was due to the suture cutting through the tendon $(n=6)$, a failure case observed in only $n=1$ specimen in group $2(P<0.001)$.

Conclusions A double-row technique combined with arthroscopic Mason-Allen/horizontal mattress stitches provides high initial failure strength and may minimize the risk of the polyethylene sutures cutting through the tendon in rotator cuff repair when a single load force is used.

Keywords Rotator cuff $\cdot$ Single-row $\cdot$ Double-row Load-to-failure $\cdot$ Sheep shoulder

\section{Introduction}

Lesions of the rotator cuff jeopardize the dynamics and stability of the rotational centre of the glenohumeral joint, lead to decentring and successively result in functional deficits of the shoulder joint. The surgical treatment of these injuries must therefore achieve stabile fibrocartilaginous integration of the tendons. This is only possible by reducing tendon tension and ensuring primary stability [16]. Nonetheless, whether an open or arthroscopic refixation technique is chosen, structural failure of the repair is one of the most common complications. Therefore, the aim is to use a suturing method that is as good as possible to ensure the repair strength.

For that reason, current studies have focused on improving the primary stability of rotator cuff repairs in order to amend tendon healing and minimize the rate of recurrent tears [1, 2, 8, 11, 13, 14, 19-23]. The most commonly used technique to date, the single-row technique, involves placing one row of suture anchors in the tendon insertion site on the humeral head. The double-row technique involves 
inserting a medial row (along the lateral cartilage boundary of the humerus) and a lateral row of suture anchors (on the lateral boundary to the anatomical insertion site). These methods are intended to enlarge the tendon-to-bone contact area and strengthen the repair by re-establishing the rotator cuff footprint [18]. Nevertheless, recent clinical studies did not find any significant functional differences between the two techniques and have not been able to confirm the mechanical results for clinical applications [6, 10, 12]. Hence, the methods for achieving stable tendon repair continue to be the subject of controversial debate.

It is questionable whether simple suture techniques (simple stitches, mattress stitches) offer sufficient stability, regardless of the number of suture anchor systems placed. This especially applies to the repair of large rotator cuff tears $[9,19]$. Therefore, complex suturing techniques are needed that provide increased tensile strength and can also be applied arthroscopically. For example, the arthroscopic Mason-Allen suture technique as described by Scheibel and Habermeyer [25], consisting of the combination of horizontal mattress sutures and single-row sutures, can be used together with contemporary, double-loaded suture anchor systems.

The present study aimed to compare the single-row suture technique for repairing rotator cuff tendons versus the double-row suture technique by subjecting two different types of sutures (braided, non-absorbable polyethylene sutures versus braided, non-absorbable polyester sutures) to biomechanical loading tests in an animal model. The peak tensile strength and stiffness of the primary tendonbone interface were evaluated. Special attention was paid to the failure mechanisms occurring in the specimens. The first hypothesis stated that the investigated single-row techniques are equivalent to the double-row techniques in terms of peak tensile strength and stiffness, regardless of the suture material used. The second hypothesis stated that all single-row and double-row repairs will withstand a defined loading of the clinically relevant $250 \mathrm{~N}$ threshold $[4,5,11]$.

\section{Materials and methods}

Immediately post mortem, 32 sheep shoulder joints (mean age of sheep: 2 years) were wrapped in wet gauze soaked in saline solution and frozen at $-20^{\circ} \mathrm{C}[13,28]$.

Before conducting the experiments, the frozen shoulders were allowed to thaw gently at room temperature for $24 \mathrm{~h}$. After dissection, the humerus was removed with the infraspinatus muscle and its intact tendon still attached. Using a scalpel, the tendon was sharply severed to simulate a standardized tear of the infraspinatus tendon. Specimens with existing rotator cuff tears were not used.
All repairs were performed using non-absorbable self-tapping suture systems with 5-mm titanium anchors (SuperRevo $^{\circledR}$, ConMed Linvatec, Largo, FL, USA). These systems were loaded with either non-absorbable, braided polyester sutures, USP No. 2 (Ethibond ${ }^{\circledR}$, Ethicon, Sommerville, NJ, USA) or with non-absorbable, braided polyethylene sutures, USP No. 2 ( $\mathrm{HiFi}^{\circledR}$, ConMed Linvatec, Largo, FL, USA).

Right and left shoulder joints were randomized to four different groups of $n=8$ specimens each:

1. Repair consisting of two rows of suture anchor systems running parallel to each other, with each row consisting of two suture anchor systems loaded with Ethibond sutures. [Suture technique: arthroscopic Mason-Allen stitches (lateral/double-loaded suture anchor system) and mattress stitches medial/single-loaded suture anchor system (Fig. 1a, b)].

2. Repair using two parallel rows of two suture anchor systems, with each row consisting of two suture anchor systems loaded with HiFi sutures. [Suture technique: arthroscopic Mason-Allen stitches (lateral/doubleloaded suture anchor system) stitches and mattress stitches medial/single-loaded suture anchor system].

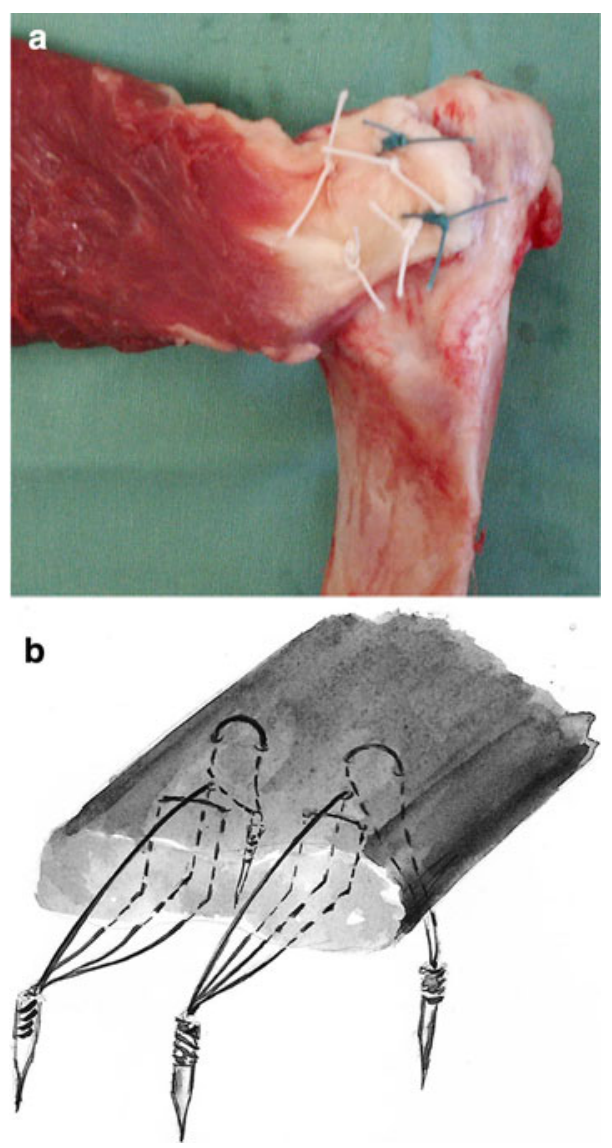

Fig. 1 Used double-row technique. The repair consists of two rows of suture anchor systems loaded with Ethibond ${ }^{\circledR}$ sutures (a). Arthroscopic Mason-Allen stitches and mattress stitches were used (b) 


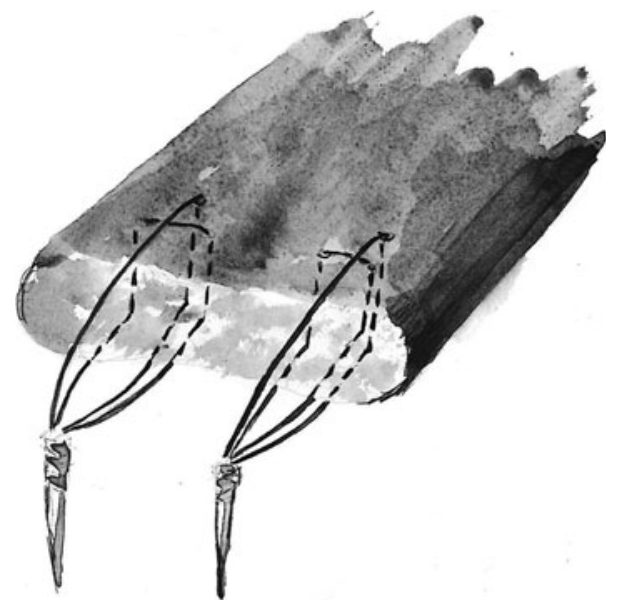

Fig. 2 Used single-row technique. The repair consists of a row with two suture anchor systems; arthroscopic Mason-Allen stitches were used

3. Repair consisting of a row with two suture anchor systems, each double-loaded with Ethibond sutures [suture technique: arthroscopic Mason-Allen stitches (Fig. 2)].

4. Repair consisting of a row with two suture anchor systems, each double-loaded with HiFi sutures [suture technique: arthroscopic Mason-Allen stitches].

In a pilot study, the insertion site of the infraspinatus tendon was evaluated to a mean size of $1 \mathrm{~cm} \times 2 \mathrm{~cm}$. The tendon was reattached to its insertion site with the anchors placed $5 \mathrm{~mm}$ apart and $5 \mathrm{~mm}$ from the distal tendon margin for single-row, and $5 \mathrm{~mm}$ from the proximal tendon margin for double-row repair (medial row) (Fig. 3a). To ensure that the suture anchor systems were placed in a standardized manner, we therefore fabricated an appropriate template (Fig. 3b). Then, the suture anchor systems were inserted into the bone at a $45^{\circ}$ angle $[3,4]$. To simulate an arthroscopic repair, we employed sutures, suture hooks and the matching instruments for placing suture anchor systems (Spectrum Tissue Repair System ${ }^{\circledR}$, ConMed Linvatec, Largo, FL, USA) and performed the procedure according to a standardized arthroscopic knot-tying technique. Each stitch was tied with the use of a sliding double half-hitch knot first, secured by a series of four reversing half-hitches on alternative posts.

The dissections and repairs were performed by a shoulder surgeon with special experience in the rotator cuff repair technique. To prevent dehydration of the tissue, the specimens were kept moist with physiological saline solution $(\mathrm{NaCl} 0.9 \%)$ throughout the entire experiment $[13,29]$.

Biomechanical loading tests

After conducting a pilot study, the biomechanical loading tests were carried out at room temperature on an electrome-

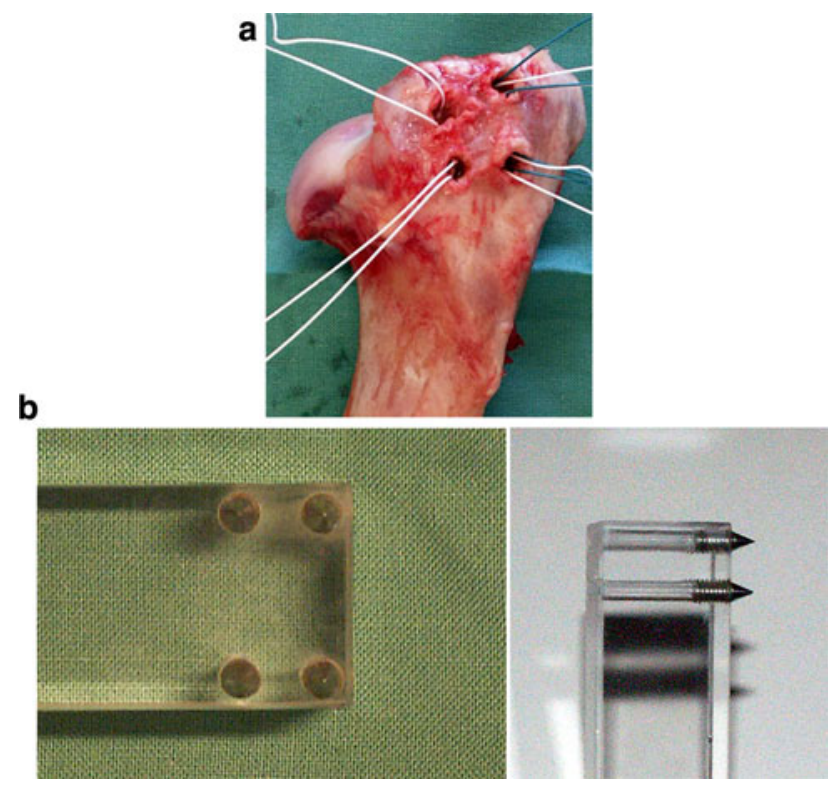

Fig. 3 Suture anchor configuration. To achieve approximately standardized conditions for all specimens, suture anchor systems were placed in a uniform manner (a) with help of a template (b)

chanical testing machine [Zwick 1445, Zwick-Roell, Ulm, Germany] in cooperation with a bioengineer (Fig. 4a). The humeri were embedded in polymethylmethacrylate (PMMA) and mounted in the holder on the testing machine to ensure that the tensile loading was applied in anatomically correct alignment tangential to the repair site.

The humeral heads were cemented into the metal holder to prevent rotation of the specimen during tensile testing. The proximal portion of the muscle was fastened in a tendon clamp (Fig. 4b). The inner side of the clamp featured recesses. The exertion of traction pressed the muscle belly into these recesses. Containers filled with dry ice attached outside the clamp kept the muscle belly frozen in such a way that its grasp was maintained and it was prevented from slipping off during tensile loading. The non-mounted portion of the muscle belly and tendon were cut to the same length on all specimens.

With the rotator cuff in normal alignment perpendicular to the longitudinal axis of the humerus, the tendon-bone interface was subjected to tensile loading $[3,4,8]$.

The construct was conditioned by applying a pretension of $10 \mathrm{~N}$ for $1 \mathrm{~min}$ with successive continuous loading of $500 \mathrm{~mm} / \mathrm{min}[13,14,26]$. The peak tensile strength $(\mathrm{N})$ and tendon dislocation at the insertion site $(\mathrm{mm})$ were evaluated by measurement amplifiers $[x$ : distance $(\mathrm{mm}) ; y$ : force $(\mathrm{N})]$ and the existing software (testXpert ${ }^{\circledR} 12$, Zwick-Roell). A digital recording of the force-dislocation curve was taken. Then, the energy-to-failure of the bone-to-stitch/suture-totendon interface was evaluated. The failure mechanism was documented, taking particular note of the tendon-to-stitch 


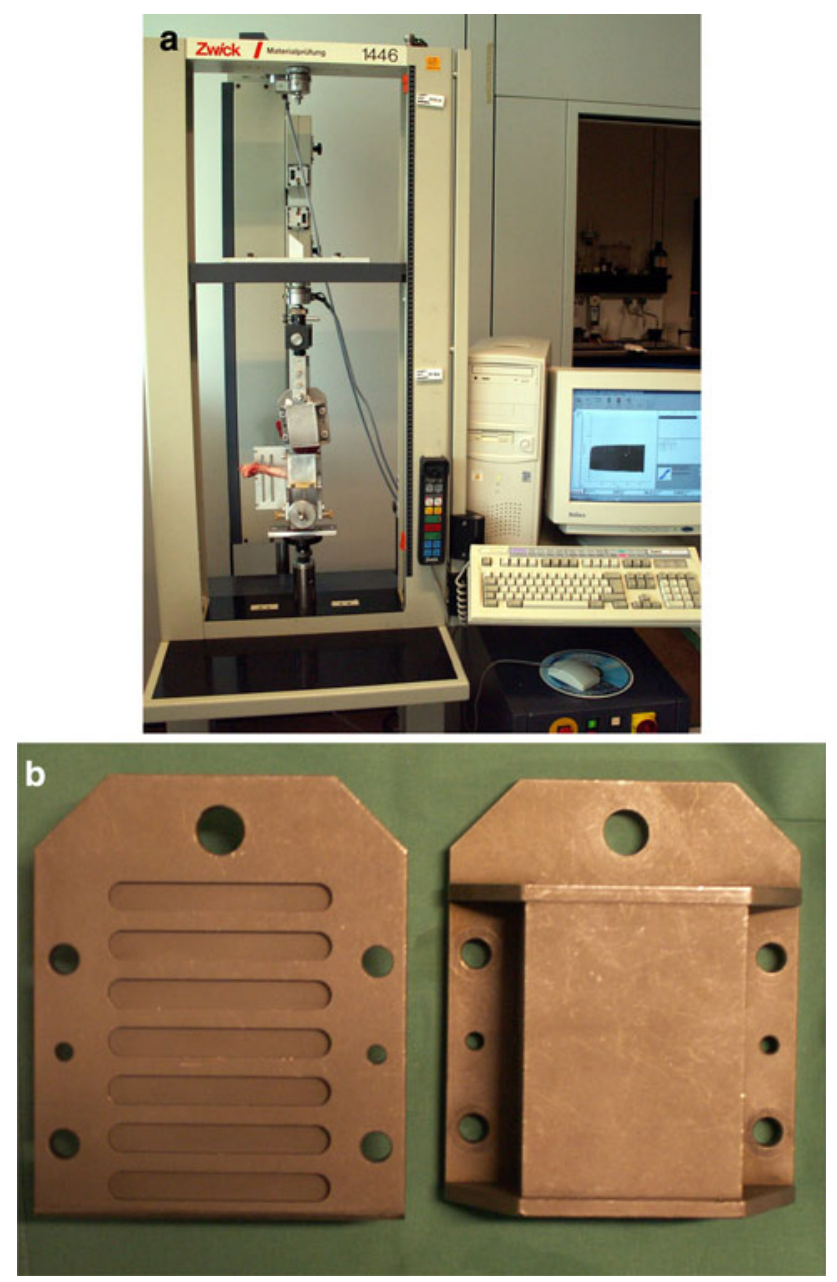

Fig. 4 Experimental set-up. Biomechanical loading tests were carried out on an electromechanical testing machine (Zwick 1445, ZwickRoell, Ulm, Germany) (a). The proximal portion of the muscle was fastened in a tendon clamp (b; left hand: inner side, right hand: external side)

interfaces and the stiffness of the repair construct was determined $(\mathrm{N} / \mathrm{mm})$. Stiffness is a measure of a tissue's behaviour in response to the type of loading that occurs in the early phase of rehabilitation and has been defined elsewhere in previous studies [1,24].

Using evidence from previous biomechanical studies on rotator cuff repairs $[4,5,11]$, a load of $250 \mathrm{~N}$ was defined as the minimally clinically relevant tensile strength (see working hypothesis 2).

\section{Statistical analysis}

SPSS Software (Rel. 13.0, SPSS, Chicago, IL, USA) was used for statistical analysis. After testing for normal distribution, the means were compared using ANOVA. The results were presented as means and standard deviation. The significance was defined at $P<0.05$.

\section{Results}

The tensile strengths averaged $254.6 \pm 42.4$ and $155.7 \pm$ $31.1 \mathrm{~N}$ in group 3 and group 4 , respectively. In the two groups with double-row technique repairs, the respective peak tensile strengths were $293.4 \pm 16.1 \mathrm{~N}$ (group 1) and $397.7 \pm 7.4 \mathrm{~N}$ (group 2$)(P<0.001$; Fig. 5$)$.

The stiffness values obtained for the tendon-bone interface showed a similar distribution. The two single-row groups exhibited the lowest stiffness (group 3: $115 \pm$ $16.7 \mathrm{~N} / \mathrm{mm}$; group 4: $84.4 \pm 19.9 \mathrm{~N} / \mathrm{mm}$ ), whereas they were the highest in the two double-row groups (group 1: $127.4 \pm 6.9 \mathrm{~N} / \mathrm{mm}$ and group 2: $162 \pm 7.3 \mathrm{~N} / \mathrm{mm}(P<0.001$; Fig. 6).

All specimens $(n=8)$ of the double-row groups (group 1 and 2) exceeded the defined limit of tensile strength of

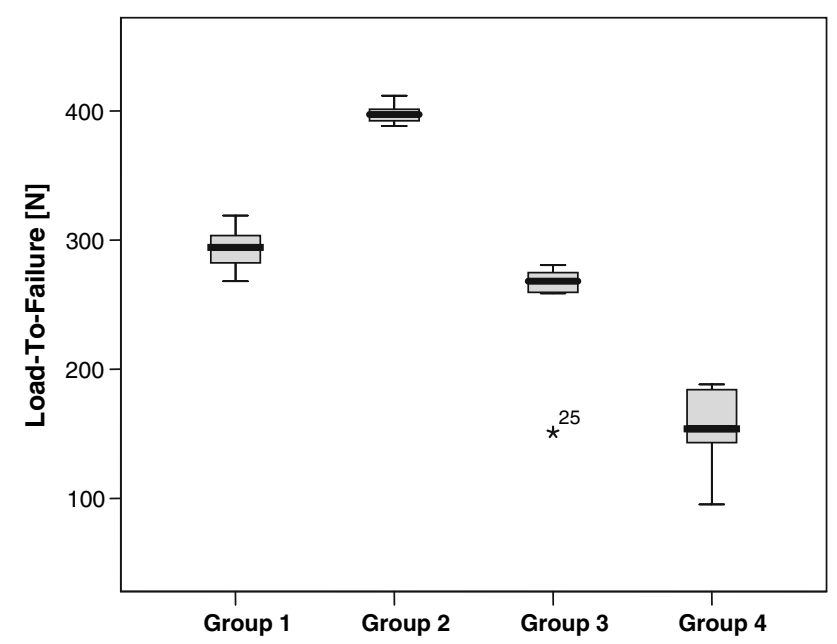

Fig. 5 Mean load-to-failure (N). Mean load-to-failure was highest in group 2 and group 1 . Group 4 only reached a mean of $155.7 \pm 31.6 \mathrm{~N}$ $(P<0.001)$

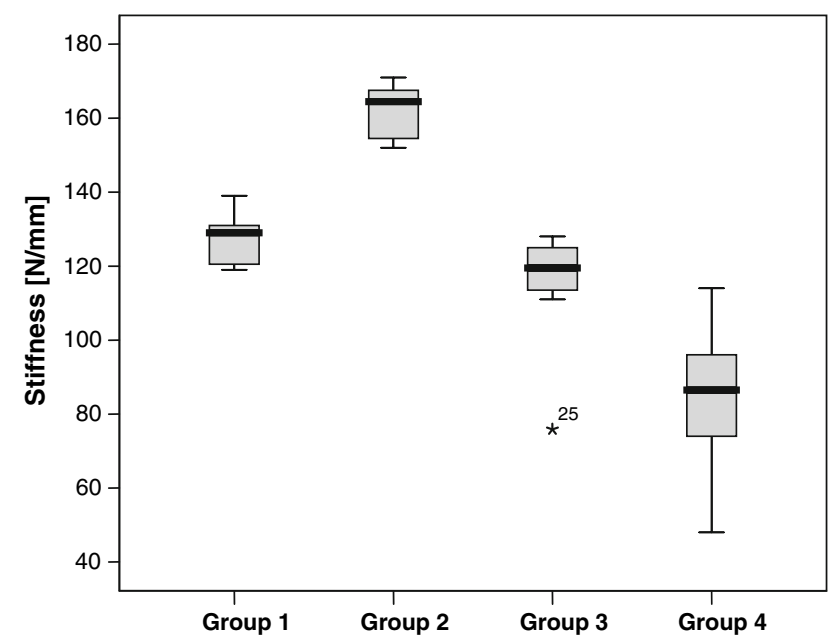

Fig. 6 Mean stiffness (N/mm). Mean stiffness was highest in group 2 and 1. Both single-row groups (group 3 and 4 ) reached lowest values for stiffness $(P<0.001)$ 


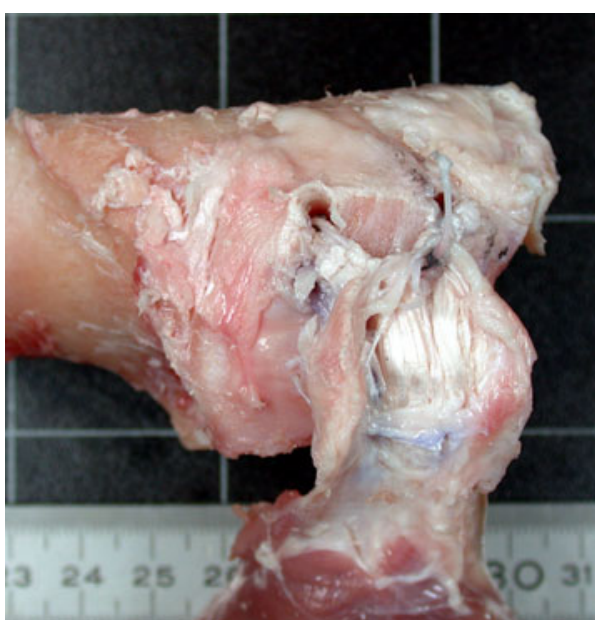

Fig. 7 Failure mechanism. Sutures cutting through the tendon leaving suture material intact

$250 \mathrm{~N}$, whereas this limit was not achieved in $n=8$ specimens of group 4 and in $n=6$ specimens of the group 3 $(P<0.001)$.

In the group 4 , we observed a relatively uniform failure pattern with the sutures cutting through the tendon in $n=6$ specimens (Fig. 7). This was also associated with failure of the tendon-bone interface, but the sutures themselves did not tear in these six specimens. In group 3 , the suture cut through the tendon in $n=3$ specimens and tore itself in $n=5$ specimens (Table 1 ). The group 2 sutures had the significantly highest tensile strength, with the sutures tearing in $n=3$ specimens at a mean load of $397.7 \mathrm{~N}$, while the sutures in $n=6$ specimens of group 1 tore at a mean load of 293.4 N (Table 1). In $n=2$ specimens of group 2, one of the suture anchor systems tilted and caused a tear at the site where the suture emerged from the bony edge. In $n=4$ specimens of this group, the tendon tore in the medial row of suture anchor systems at the transition to the muscle belly. The maximum tensile strength occurred in these specimens. Table 1 presents the failure mechanisms of the repair groups.

\section{Discussion}

The aim of the study was to compare the primary peak tensile strength and stiffness of the single-row technique for rotator cuff repairs with the double-row technique using a load-to-failure testing. The hypothesis that the single-row techniques would achieve a peak tensile strength equivalent to the double-row techniques, regardless of the type of suture material used, was not confirmed (group $2>$ group $1>$ group $3>$ group 4 ). Additionally, none of the specimens in the group $4(n=8)$ achieved the defined tensile strength limit of $250 \mathrm{~N}$, as was the case with the $n=6$ specimens in group 3. By contrast, the results of the tensile strength of all specimens of group 1 and group 2 were markedly above this limit $(P<0.001)$. There were also significant differences observed in the failure rates of the suture materials used. The braided non-absorbable polyethylene sutures, used in the double-row technique, demonstrated a significantly higher tensile strength and stiffness compared to the other cuff repair methods tested $(P<0.001)$. The suture material was observed to cut through the tendon in $n=1$ specimen only, whereas this failure occurred in $n=6$ cases sutured using the single-row technique (group 4). Unlike the results regarding the discrepancy between single- and double-row repairs in the

Table 1 Mechanism of failure of the repaired specimen including mean load-to-failure $(\mathrm{N})$ and mean stiffness $(\mathrm{N} / \mathrm{mm})$

\begin{tabular}{|c|c|c|c|}
\hline Group & Load-to-failure (N) & Stiffness (N/mm) & Failure mode \\
\hline Group 1 & $293.4 \pm 16.13$ & $127.4 \pm 6.9$ & $\begin{array}{l}\text { Tendon tore at tendon-muscle junction, repair intact }(n=2) \\
\text { Suture anchor system tilted and suture tore at bony ridge }(n=1) \\
\text { Torn suture at eyelet }(n=2) \\
\text { Torn sutures }(n=3)\end{array}$ \\
\hline Group 2 & $397.7 \pm 7.4$ & $162 \pm 7.3$ & $\begin{array}{l}\text { Tendon tore at tendon-muscle junction, repair intact }(n=4) \\
\text { Suture anchor system tilted and suture tore at bony ridge }(n=2) \\
\text { Torn suture }(n=1) \\
\text { Sutures cutting tendon, sutures intact }(n=1)\end{array}$ \\
\hline Group 3 & $254.6 \pm 42,4$ & $115 \pm 16.7$ & $\begin{array}{l}\text { Sutures cutting tendon, sutures intact }(n=3) \\
\text { Torn suture at eyelet }(n=1) \\
\text { Torn sutures }(n=3) \\
\text { Suture anchor system tilted and suture tore at bony ridge }(n=1)\end{array}$ \\
\hline Group 4 & $155.7 \pm 31.1$ & $84.4 \pm 19.9$ & $\begin{array}{l}\text { Suture anchor system tilted }(n=1) \\
\text { Torn sutures }(n=1) \\
\text { Sutures cutting tendon, sutures intact }(n=6)\end{array}$ \\
\hline
\end{tabular}


study on hand, Nelson et al. [23] found no differences between single- and double-row repairs with cyclic loading also using a sheep model. They assumed that the used forces in their experimental set-up were too low to show a difference between the two groups. Additionally, authors use cyclic loading forces in contrast to the study on hand.

In clinical practice, abrupt loading to the repaired rotator cuff leads to a reduction in the tensile strength of the repair [1]. Thereby, one involuntary movement of the shoulder joint in the early postoperative phase can lead to partial or complete failure of the tendon-bone interface and thereby imperil the fibrocartilaginous reintegration of the tendon. For that reason, the use of monotone loading in conjunction with the determination of the peak tensile strength and stiffness of the repair construct is equally as mandatory for evaluating a repair technique, as Burkhead et al. have shown [5]. A more even load distribution can be achieved by placing multiple fixation points (double-row) at the tendon-bone interface. This increases the contact pressure area with the result of a higher tensile strength [2]. However, at high loads a point is reached where the suture material itself becomes the weakest link in the interface [7]. By developing non-absorbable, braided polyethylene sutures, this can be avoided in favour of higher peak tensile strengths [7, 29]. The tensile strength of this suture material reaches values of more than $300 \mathrm{~N}$ and is 2.5 -fold higher than braided polyester sutures [29]. Notwithstanding this fact, the singlerow technique with polyethylene sutures (group 4) in our study reached a mean of $155 \mathrm{~N}$ only. The double-row technique with the same suture material (group 2) reached values approaching $400 \mathrm{~N}$. This contradicts the findings obtained by Baleani et al. [1], who observed that the use of a polyethylene suture resulted in a significantly increase in tensile strength even with the single-row technique. In our study, failure in $n=6$ specimens of group 4 , with low tensile strength values, was caused by the sutures cutting through the tendon without the suture material itself breaking. By contrast, when the double-row technique was used with polyethylene sutures (group 2), the sutures only cut through the tendon in $n=1$ specimen. This finding confirms the results of Kowalsky et al. [15] who demonstrated increased tendon abrasion properties for polyethylene sutures caused by the sutures cutting through the tendon early. It is our understanding that this abrasion should have an even stronger effect under cyclical loading. Consequently, it would be of interest to analyse the behaviour of the polyblended suture material during cyclic loading as well, because this setting will represent the physiological loading conditions. By contrast, in the current investigation only a single load-to-failure mode was used, which is certainly a limitation of the study design. Indeed, the monotone loading impulses we used caused the suture to cut directly through the tendon when traction was applied.
Therefore, in our judgment, it is more likely that rigid polyethylene sutures have a splitting effect at the tendon ends when a single load force is used. Even though it is difficult to transfer the results of biomechanical studied directly to clinical routine, we believe that polyethylene sutures should be reserved for cases where multiple fixation points are used to evenly distribute the load and the primary stability of the interface is enhanced by selecting a complex suture technique. This will minimize the risk of the suture material cutting through the tendon and thereby prevent failure under low tensile loads (Table 1).

Although its histological and structural properties make the infraspinatus tendon of the sheep a valid model for studying repair techniques for human rotator cuffs $[8,11$, $13,14,17,23,26]$, one should consider that healthy tendons were used here. In other words, the clinical picture of a persistent tear was not simulated. Thus, it can be predicted that failure caused by the suture cutting through the tissue will happen even earlier when rigid polyethylene sutures are used in clinical applications on degenerated and atrophied human tendons.

In $n=4$ specimens of group 2, we observed a tear along the medial row of suture anchors. A similar observation was made in a recent clinical study conducted by Trantalis et al. [27]. Since the medial row of suture anchors is tension bearing in the double-row technique, this might be viewed as a potential cause for failure, a finding that was confirmed in a biomechanical study of Mazzocca et al. [21]. Despite the above, the extent to which circulation in the medial insertion of the tendon is compromised by double-row repair still needs to be investigated in in vivo studies. Additionally, studies investigating the suture-bridge technique might also be interesting in this context.

\section{Conclusion}

Our study showed that the double-row technique exhibits higher primary tensile strength and stiffness under peak tensile loading compared with the single-row technique. The combination of a complex suture technique with four anchorage points can result in higher failure strength values and therefore may prevent rigid polyethylene sutures (represented here by HiFi sutures) from cutting through the tendon at low stresses and thereby prevent early repair failure. Nevertheless, future in vivo studies need to confirm whether these advantages also apply to tendon healing and will thereby lower re-tear rates. Not until then will it be possible for the double-row technique to be used to prevent cost-intensive revision surgeries.

Acknowledgments The work was founded by the Research Program, University of Göttingen Medical Centre (UMG), 
Georg-August-University, Germany. The authors acknowledge Mrs G. Wolf-Bergk for creating the anatomical line drawings in this report.

Conflict of interest statement The authors declare that they have no conflict of interest.

Open Access This article is distributed under the terms of the Creative Commons Attribution Noncommercial License which permits any noncommercial use, distribution, and reproduction in any medium, provided the original author(s) and source are credited.

\section{References}

1. Baleani M, Ohmann C, Guandalini L, Rotini R, Giavaresi G, Traina F, Viceconti M (2006) Comparative study of different tendon grasping techniques for arthroscopic repair of the rotator cuff. Clin Biomech (Bristol, Avon) 21:799-803

2. Baums MH, Spahn G, Steckel H, Fischer A, Schultz W, Klinger H-M (2009) Comparative evaluation of the tendon-bone interface contact pressure in different single- versus double-row suture anchor repair techniques. Knee Surg Sports Traumatol Arthrosc. doi:10.1007/s00167-009-0771-7

3. Burkhart SS (1995) The deadman theory of suture anchors: observations along a south Texas fence line. Arthroscopy 11:119-123

4. Burkhart SS, Johnson TC, Wirth MA, Athanasiou KA (1997) Cyclic loading of transosseous rotator cuff repairs: tension overload as a possible cause of failure. Arthroscopy 13:172-176

5. Burkhead WZ, Skedros JG, O'Rourke PJ, Pierce WA, Pitts TC (2007) A novel double- row rotator cuff repair exceeds strengths of conventional repairs. Clin Orthop Relat Res 461:106-113

6. Charousset C, Grimberg J, Duranthon LD, Bellaiche L, Petrover D (2007) Can a double-row anchorage technique improve tendon healing in arthroscopic rotator cuff repair? Am J Sports Med 35:1247-1253

7. DeCarli A, Vadala A, Monaco E, Labianca L, Zanzotto E, Ferretti A (2005) Effect of cyclic loading on new polyblend suture coupled with different anchors. Am J Sports Med 33:214-219

8. Demirhan M, Atalar AC, Kilicoglu O (2003) Primary fixation strength of rotator cuff repair techniques: a comparative study. Arthroscopy 19:572-576

9. Domb BG, Glousman RE, Brooks A, Hansen M, Lee TQ, ElAttrache NS (2008) High-tension double-row footprint repair compared with reduced-tension single-row repair for massive rotator cuff tears. J Bone Joint Surg Am 90A(Suppl 4):35-39

10. Franceschi F, Ruzzini L, Longo UG, Martina FM, Zobel BB (2007) Equivalent clinical results of arthroscopic single-row and double-row suture anchor repair for rotator cuff tears. Am J Sports Med 35:1254-1260

11. Gerber C, Schneeberger AG, Beck M, Schlegel U (1994) Mechanical strength of repairs of the rotator cuff. J Bone Joint Surg Br 76B:371-380

12. Grasso A, Milano G, Salvatore M, Falcone G, Deriu L, Fabbriciani C (2009) Single-row versus double-row arthroscopic rotator cuff repair: a prospective randomized clinical study. Arthroscopy $25: 4-12$

13. Klinger HM, Steckel H, Spahn G, Buchhorn GH, Baums MH (2007) Biomechanical comparison of double-loaded suture anchors using arthroscopic Mason-Allen stitches versus traditional transosseous suture technique and modified Mason-Allen stitches for rotator cuff repair. Clin Biomech (Bristol, Avon) 22:106-111
14. Klinger HM, Buchhorn GH, Heidrich G, Kahl E, Baums MH (2008) Biomechanical evaluation of rotator cuff repairs in a sheep model: Suture anchors using arthroscopic Mason-Allen stitches compared with transosseous sutures using traditional modified Mason-Allen stitches. Clin Biomech (Bristol, Avon) 23:291-298

15. Kowalsky MS, Dellenbaugh SG, Erlichman DB, Gardner TR, Levine WN, Ahmad CS (2008) Evaluation of suture abrasion against rotator cuff tendon and proximal humerus bone. Arthroscopy 24:329-334

16. Kessler MA, Lichtenberg S, Habermeyer P (2003) Reconstruction of big rotator cuff ruptures. a new technique of tendon refixation with the corkscrew suture anchor system. Unfallchirurg 106:826833 [German]

17. Lewis CW, Schlegel TF, Hawkins RJ, James SP, Turner AS (2001) The effect of immobilization on rotator cuff healing using modified Mason-Allen stitches: a biomechanical study in sheep. Biomed Sci Instrum 37:263-268

18. Lo IK, Burkart SS (2003) Double-row arthroscopic rotator cuff repair: re-establishing the footprint of the rotator cuff. Arthroscopy 19:1035-1042

19. Ma CM, Comerford L, Wilson J, Puttlitz CM (2006) Biomechanical evaluation of arthroscopic rotator cuff repairs: double-row compared with single-row fixation. J Bone Joint Surg Am 88A:403-410

20. Mahar A, Tamborlane J, Oka R, Esch J, Pedowitz RA (2007) Single-row suture anchor repair of the rotator cuff is biomechanically equivalent to double-row repair in a bovine model. Arthroscopy 23:1265-1270

21. Mazzocca AD, Millet PJ, Guanche CA, Santangelo SA, Arciero RA (2005) Arthroscopic single-row versus double-row suture anchor rotator cuff repair. Am J Sports Med 33:1861-1868

22. Milano G, Grasso A, Zarelli D, Deriu L, Cillo M, Fabbriciani C (2008) Comparison between single-row and double-row rotator cuff repair: a biomechanical study. Knee Surg Sports Traumatol Arthrose 16:75-80

23. Nelson CO, Sileo MJ, Grossmann MG, Serra-Hsu F (2008) Single-row modified Mason-Allen versus double-row arthroscopic rotator cuff repair: a biomechanical and surface area comparison. Arthroscopy 24:941-948

24. Rickert M, Witzel U, Kölbel R, Georgousis H (2002) Primary strength of conventional and alternative suture techniques of the rotator cuff. A biomechanical study. Unfallchirurg 105:23-30 [German]

25. Scheibel MT, Habermeyer P (2003) A modified Mason-Allen technique for rotator cuff repair using suture anchors. Arthroscopy 19:330-333

26. Schlegel TF, Hawkins RJ, Lewis CW, Turner AS (2007) An in vivo comparison of the modified Mason-Allen suture technique versus an inclined horizontal mattress suture technique with regard to tendon-to-bone healing: a biomechanical and histological study in sheep. J Shoulder Elbow Surg 16:115-121

27. Trantalis JN, Boorman RS, Pletsch K, Lo IKY (2008) Medial rotator cuff failure after arthroscopic double-row rotator cuff repair. Arthroscopy 24:727-731

28. Woo S, Orlando CA, Camp JF, Akeson WH (1986) Effects of postmortem storage by freezing on ligament tensile behavior. J Biomech 19:399-404

29. Wüst DM, Meyer DC, Favre P, Gerber C (2006) Mechanical and handling properties of braided polyblend polyethylene sutures in comparison to braided polyester and monofilament polydioxanone sutures. Arthroscopy 22:1146-1153 